\title{
HISTORICAL BUILDINGS MODELS AND THEIR HANDLING VIA 3D SURVEY: FROM POINTS CLOUDS TO USER-ORIENTED HBIM
}

\author{
F. Chiabrando ${ }^{\text {a }}$, G. Sammartano ${ }^{\text {a* }}$, A. Spanò ${ }^{a}$ \\ ${ }^{\text {a }}$ Politecnico di Torino, DAD, 10129, Torino, Italy - (filiberto.chiabrando, giulia.sammartano, antonia.spano)@polito.it
}

Commission V, WG V/4

KEY WORDS: HBIM, Points Clouds, LiDAR, Object Recognition, Cultural Heritage, Interoperability.

\begin{abstract}
:
This paper retraces some research activities and application of 3D survey techniques and Building Information Modelling (BIM) in the environment of Cultural Heritage. It describes the diffusion of as-built BIM approach in the last years in Heritage Assets management, the socalled Built Heritage Information Modelling/Management (BHIMM or HBIM), that is nowadays an important and sustainable perspective in documentation and administration of historic buildings and structures.

The work focuses the documentation derived from 3D survey techniques that can be understood like a significant and unavoidable knowledge base for the BIM conception and modelling, in the perspective of a coherent and complete management and valorisation of $\mathrm{CH}$. It deepens potentialities, offered by 3D integrated survey techniques, to acquire productively and quite easily many 3D information, not only geometrical but also radiometric attributes, helping the recognition, interpretation and characterization of state of conservation and degradation of architectural elements. From these data, they provide more and more high descriptive models corresponding to the geometrical complexity of buildings or aggregates in the well-known 5D (3D + time and cost dimensions).

Points clouds derived from 3D survey acquisition (aerial and terrestrial photogrammetry, LiDAR and their integration) are reality-based models that can be use in a semi-automatic way to manage, interpret, and moderately simplify geometrical shapes of historical buildings that are examples, as is well known, of non-regular and complex geometry, instead of modern constructions with simple and regular ones. In the paper, some of these issues are addressed and analyzed through some experiences regarding the creation and the managing of HBIM projects on historical heritage at different scales, using different platforms and various workflow. The paper focuses on LiDAR data handling with the aim to manage and extract geometrical information; on development and optimization of semi-automatic process of segmentation, recognition and modelling of historical shapes of complex structures; on communication of historical heritage by virtual and augmented reality (VR/AR) in a 3D reconstruction of buildings aggregates from a LiDAR and UAV survey. The HBIM model have been implemented and optimized to be managed and browse by mobile devices for not only touristic or informative scopes, but also to ensure that HBIM platforms will become more easy and valuable tools helping all professionals of AEC involved in the documentation and valorisation process, that nowadays more and more distinguish $\mathrm{CH}$ policies.
\end{abstract}

\section{INTRODUCTION}

As a part of Cultural Heritage enhancement process, the 3D digital modelling of historical structures play a more and more crucial role for the monitoring of the documentation and restoration phase, mainly looking forward a continuous control in spatial-temporal dimension (Barazzetti et al., 2015a; Dore et al., 2015; Baik et al., 2014; Oreni, 2014; Ludwig et al., 2013.) and for popular-informative and educational purposes (Barazzetti et al., 2015b; Quattrini et al, 2015; Barazzetti et al., 2014.).

Reality-based spatial data from advanced geomatics techniques can provide an accurate reproduction of objects, as well as, the uniqueness and the specificities of each cultural asset impose a careful choice of the needed approximation (Quattrini et al., 2015; Fai \& Rafeiro, 2014). From this standpoint, 3D survey output as point cloud from terrestrial LiDAR acquisition or photogrammetric acquisition and image-matching elaboration are increasingly used and examined as direct source of a large amount of data concerning each information: punctual geometric characteristics and semantic data about objects and sub-objects.

In particular, 3D points clouds models, with their spatial and radiometric data (also temporal information, in case of progressive survey) help to obtain the 2D and 3D generation geometry, which guarantee appropriateness of geometrical accuracy., and to obtain all correlate information, to complete the semantic definition. (Quattrini et al, 2015).

* Corresponding author
Some issues regarding interoperability of data and geometric approximation of architecture, however, are still open. In fact for the parametric modelling of $\mathrm{CH}$, the control of LoD (Level of Development), the structural elements complexity level and the predetermined discretization of the model is fundamental (Barazzetti et al., 2015a). The BIM interoperability needs are addressed with the IFC standards (Industry Foundation Classes) BuildingSMART that is all about the sharing of information between project team members and across the software applications. Maybe non-regular shapes have to be analysed and modelled outside of the BIM software, starting from irregularity of reality-based point cloud data. Because of this, many problems of interoperability take over, between not only BIM software but also concerning platforms of different disciplines involved in the model design. Many research in this context, moving from lack and issues correlated to ever-growing need of stakeholders involved in BIM development, HBIM design, geomatics research and Cultural Heritage enhancement (Hichri et al, 2013). In this scenario, the new conception of documentation has thus to be conceived as a long-lasting process in buildings life and for this reasons, documentation systems must be adapted and improved to these needs. The future of 3D model is the real-time handling and the direct upgrading of information into the HBIM database, but experiences of BIM approach for Heritage documentation and conservation are still not very developed, rather than in new buildings design ones (Del Giudice \& Osello, 2013). 


\section{STATE OF THE ART}

Born in the building design context for parametric modelling, BIM platforms developed his algorithms and software over the last years in Architecture Engineering and Construction (AEC) industry management for new buildings. Nowadays BIM is largely settled and useful in the context of Facility Management (FM) activities on existing buildings, the so-called "as-built BIM" (Macher et al., 2015; Volk et al, 2014;Tang, 2010). BIM on real objects enables the monitoring of all design and life cycle assessment, maintenance, refurbishment, deconstruction, end-oflife considerations and side-analysis (contact-less or invasive analysis: energetic efficiency, structural, materical...) (Volk et al, 2014). Hence, BIM model in recent years aids to show comprehensive potential simulations of behaviour of all these various disciplines involved in the building process of FM (Quattrini et al, 2015).

In early XXI the first HBIM was developed (Murphy et al, 2009) like a new prototype-system of BIM, a modelling of historic structures as parametric objects in a database "library". These objects can be collected and moulded in the reverse engineering process, creating full 2D and 3D models including details behind the object's surface, concerning its methods of construction and material makeup. Information are taken on the base of 3D realitybased data from point clouds, by automatic or semi-automatic recognition. (Murphy et al, 2012)

HBIM, it can easily be seen in scientific domain, are more and more powerful tools for the entire enhancement process, from documentation, restoration, up to development of $\mathrm{CH}$ (Logothetis, 2105; Fai et al., 2011). Specific HBIM made up on existing historical buildings are able today to encapsulate into their own database a high level of multiple information, not only geometric but also the ones about historic evolution, material composition, stratigraphy, state of conservation, technological and structural behaviour of elements, and therefore they can be useful for different scopes. Research works in the field of HBIM can lead to many application and above all, for example: 3D detailed models for divulgative purposes; base models for historical constructive phases study; 3D models for interpretation, reconstruction and restoration design; management and monitoring of the state of conservation of structures and materials; base model for archive and relate various diagnostic test to the geometry; static and dynamic condition assessment by structural simulation and Finite Element Analysis (FEA); etc...(Barazzetti et al, 2015a; Dore et al., 2015; Sun et al, 2015) Research activity about city and heritage models develops also, parallel to HBIM, towards Virtual Reality and Augmented Reality, and handling and integration of HBIM structure with models in 3D GIS and 3D CityGML standards, for further management and advanced analysis (Baik et al., 2015; Barazzetti et al, 2015b; El Meouche et al, 2013; Saygi at, al 2013; Dore et al, 2012).

\section{BUILDING AND MANAGING INFORMATION INTO HBIM}

As is well known BIM spaces differs from common 3D modelling founded from 1970s on computer-aided design (CAD), in its possibility to control 5D (3D spatial model with quantity control, with time scheduling, and with cost calculation) of objects. They are "intelligent" thanks to the additional information data that are stored into the database (Eastman et al, 2008).

\subsection{BIM and HBIM}

"Building Information Modeling" is an object-oriented (and not only surface) organized space, managed from different available software, and consists of parametric objects representing building components, described through construction techniques, materials, historical data, photographs, audio, etc .. (Barazzetti et al, 2014; Eastman et al, 2008). It is defined by international standards as "shared digital representation of physical and functional characteristics of any built object [...] which forms a reliable basis for decisions". (ISO standard 29481-1: 2010 E)

Starting from this concept, we define HBIM as a semantic-aware database regarding historic buildings, in which the geometric model is connected to descriptive information multi-source. (Quattrini et al, 2015). Architectural shapes have to be recognized and segmented from the point cloud acquired by LiDAR or photogrammetry to be embedded in the HBIM. Parametrization according to BIM approach, is more complex when it regards existing buildings with heterogeneous geometries: they have to be remodelled manually since automatic recognition now is not effectively available and developed.

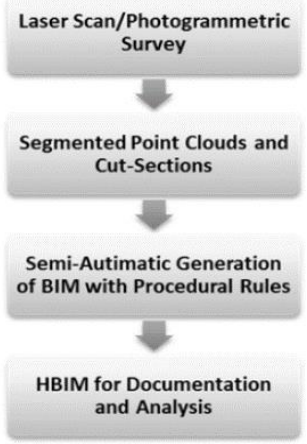

Figure 1. Workflow of as-built BIM modeled on Cultural Heritage site (HBIM), from (Dore et al. 2015)

The sample-workflow for the definition of a HBIM starts from data acquisition, from different sensors according to the context needs and the required outputs. Then, the points cloud have to be pre-processed and reduced with various systems and dedicated software, and maybe adapted for next segmentation because it is possible an automatic or semi-automatic recognition of objects into HBIM platform. Elements will be modelled and converted into an approximation of reality according to parametric rules, so it is possible to adapt in each instance of the model. Finally the shapes and the identity of objects must be linked by accurate and stiff relationship according to the semantic definition of entities. At this moment, the model is ready to be explored and implemented with other information for the site analysis and monitoring during time. Nevertheless, today the manual creation of As-built BIM is complex for time, cost, skills processing, and automatic or semi-automatic tools are needed (Quattrini et al, 2015; Tang et al, 2010).

BIM platforms and algorithms to organize a 3D database on Cultural Heritage can be classified generally according to their tools: $3 D$ modellers; viewers; analysers, and they can be commercial software or open-source software. The commercial ones used in the context of $\mathrm{CH}$ are: GraphiSoft ArchiCAD, Autodesk Revit, Bentley MicroStation V8i and Tekla Structures. The open-source ones are less than commercial ones: Edificius, Tekla BIMsight, Autodesk Navisworks Freedom. (Logothetis, 2015). Anyway for the conception of a HBIM, until today, is not possible yet to manage the entire workflow in a single platform, and solution for interoperability requirements are expected by research activity.

\subsection{Knowledge into HBIM: type of information}

For the organization of an as-Built BIM (Volk et al. 2014; Tang et al, 2010), as it is a Heritage BIM or BHIMM (Built Heritage Information Modelling/Management) there are three usual steps: Data collection 


\section{Data preprocessing \\ BIM modelling}

Then there are three central task by which organize and represent the knowledge about the Historic building in the BIM modelling:

The modelling of shapes

The modelling/recognition/categorization of objects

The modelling of relationship between objects

3.2.1 Shape. The shape representation can be done according to three features: firstly, in a Parametric/non-parametric way according to a set of variable parameters to define a model-type. (Garagnani et al, 2013). Then the modelling of objects can be developed in a Global/Local dimension, it it carachterize the entire object or a portion of it. The representation can be then Explicit/Implicit. As it is known, Explicit shape representation is as B-REP, a representation of geometries from boundary and definition; contrariwise, implicit representation is mostly used for entities definition and recognition, by several types of more or less diffuse algorithms. (Logothetis, 2015; Tang et al, 2010)

3.2.2 Recognition. The recognition of objects includes object identification, extraction of relational and semantic information as well as treatment of concealments and remaining clutter. Methods and tools of object recognition differ due to geometric complexity of the building, required LoD, and applied capturing technique, data format, or processing time. (Volk et al. 2014).

3.2.3 Relationship. The relationship is important to define characteristics of model and it is crucial also in the phase of object recognition. (Tang et al, 2010)

Semantic relation between object are:

- Relationship of aggregation

Topological relationship

Relationship of direction

\section{GEOMETRY GENERATION IN HBIM}

The great challenge of modelling the shape of an object-oriented space on existing buildings is the uniqueness of those objects, and this also greatly influences organization of $3 \mathrm{D}$ data collection and the choice of acquisition technique, by TLS or photogrammetry. So, for HBIM, modelling shapes faithful to geometry is the first task to obtain a useful result. In their 2009 work, Chevrier and Maillard say that only simple geometric shapes are automatically adjusted within point clouds, and only the visible parts of objects can be modeled and reconstructed. The hidden parts are often predictable and can be created as parametric objects based on historical data architecture. Architectural knowledge, geometric and historical are necessary to create the architectural elements.

\subsection{Shape knowledge for geometric modelling}

In this context "Modelling" denotes the creation of BIM objects that represent building components, including both geometric and non-geometric attributes and relationships. If BIM is modelled on the basis of previously captured building information, the previous data capture, processing and recognition methods influence the data quality through the deployed technique and the provided LOD related to interoperability issue. (Fai \& Rafeiro, 2014; Volk et al. 2014). Data interoperability is a key enabler to achieving the goal of a buildingSMART process. BuildingSMART has developed a common data schema (IFC) that makes it possible to hold and exchange relevant data between different software applications ( http://www.buildingsmart.org/standards/technical-vision/openstandards-101/). The American Institute of Architects (AIA) is the developer of the standardized protocol of Level Developmen in BIM landscape, in particular it divided this formal language in five levels of development: LoD 100 (elementary representation); LoD 200 (generic models); LoD $300+350$ (executive planning); LoD 400 (construction planning); LoD 500 (as-built). (BIM FORUM, Level of Development Specifcation, 30 October, 2015).

In the BIM model shapes can be created manually or automatically, on the point cloud or on the triangulate mesh (Lari, 2011. Tang et al, 2010). Some of the most employed solution for commonly solve the reality representation from point cloud are:

- Model volumes and shaped from scratch (manual)

- $\quad$ Fitting primitives to the point clouds (semi-automatic)

- Make cross sections and surface extrusion (semi-automatic)

(Chiabrando et al, 2015; Quattrini et al, 2015; Barazzetti et al, 2015; Oreni et al, 2013)

The problem of streamline the modelling process of existing building is often solved now with reverse-engeneering approach to capture information reality-based (Volk et al. 2014). For example we met "points-to-BIM", "scan-to-BIM", "Re-capture", "poitSense" software.

The solution for the representation of geometries is:

- Simple shapes (from SW menu and functionalities)

- Complex shapes (creation of parametric object from metric data of processing of the point cloud) (Baik et al, 2014)

- Unique shapes (create ad-hoc with B-rep algorithms, or viaNURBS) (Quattrini et al, 2015)

\subsection{Geometry generation: semi-automation and auto- recognition}

The recognition of objects in the HBIM project includes object identification, extraction of relational and semantic information. Methods and tools of object recognition differ due to geometric complexity of the building, required LoD, and applied capturing technique, data format, or processing time. Nowadays many methods supported by algorithms are available.

(Volk et al. 2014. Tang et al, 2010)

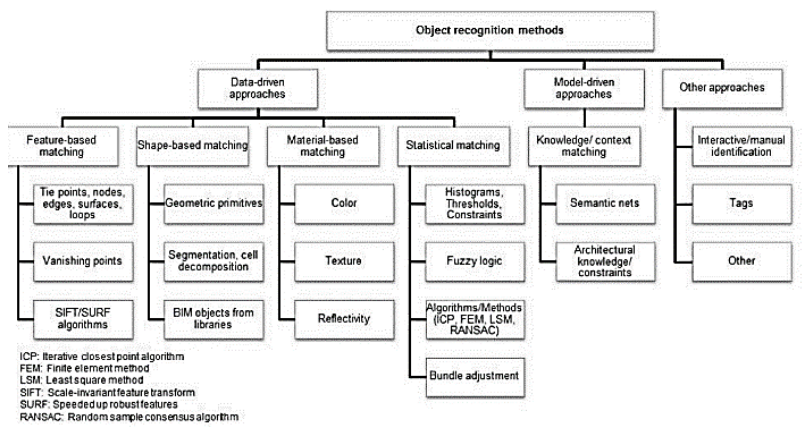

Figure 2. Summary of algorithms for object recognition approaches on existing buildings, from (Volk et al. 2014)

4.2.1 A first case study using cross sections and surface extrusion from the point clouds (semi-automatic). The historical building chosen for the test is a portion of the Castle of Valentino in Turin, one of the city symbols and headquarters of the Architecture area of studies of the Politecnico di Torino. The Valentino Castle is placed on the left side of the river Po, and nowadays it is fully included in the city. The Castle has an ancient origin, though the first official reference to it dates 1543 . The Duke of Savoy acquired the asset composed of a palace with garden and, starting from 1620, Christine of France charged the architect Carlo di Castellamonte with some main extension works, including the doubling of the central body and the realization of the towers. 
More precisely, the BIM modelling stood in the basement, currently destined for stores and depots, but in the past was the reception rooms of the palace looking out towards the river.

For the modeling of the foundation area of the castle it was used the Revit software which in its basic configuration does not read point clouds and does not use NURBS modeling. It was necessary to make simplifications and take the measures that have allowed to represent the architectural elements through a schematic that has alienated the model by a closeness to reality similar to that permitted by the software dedicated to the manipulation of the clouds.

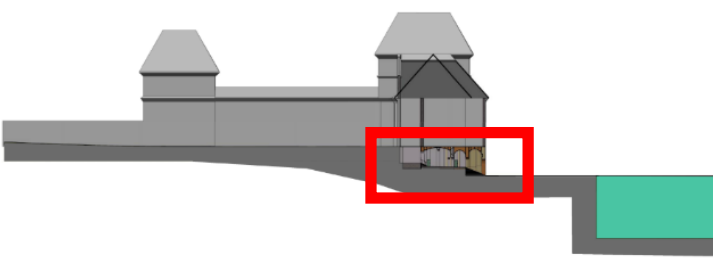

Figure3. HBIM model of the Valentino Castel (Turin) and focus on the HBIM model of "hall of columns"

The vertical elements has been modelled using the local families as the masonry modeling showed a marked surface irregularities. In place families are in fact the category of objects including all the elements which, by their nature and their use, are considered unique in its kind.
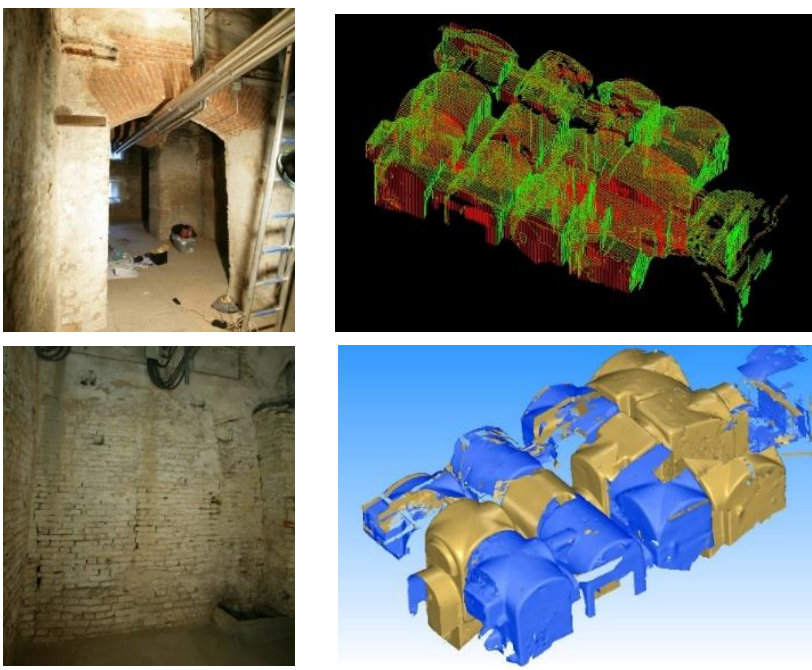

Figure 4. Photos from the ancient structure and image of the section elaboration and mesh creation

The high irregularity of the walls have been carefully studied on Lidar model, configured in continuous surface (mesh), or have been studied carefully the section profiles from which it is built the model in BIM platform using mainly extrusion and subtraction functions. The gates in the walls were modeled with similar functions.

Modeling the pavilion vault with lunettes of the rooms dating back to the sixteenth century is quite complex because the software does not have the appropriate tool. Basically it was necessary to create a floor that has been emptied by subtraction with surfaces from the geometry constructed by generating and guiding the turn surfaces obtained from the point cloud.
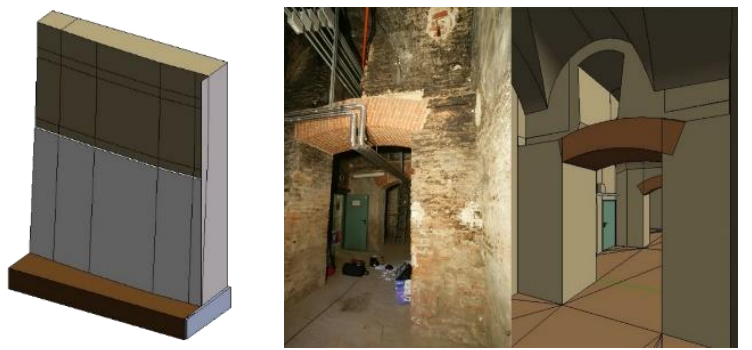

Figure 5. Modeling of the irregular wall in the Castle underground
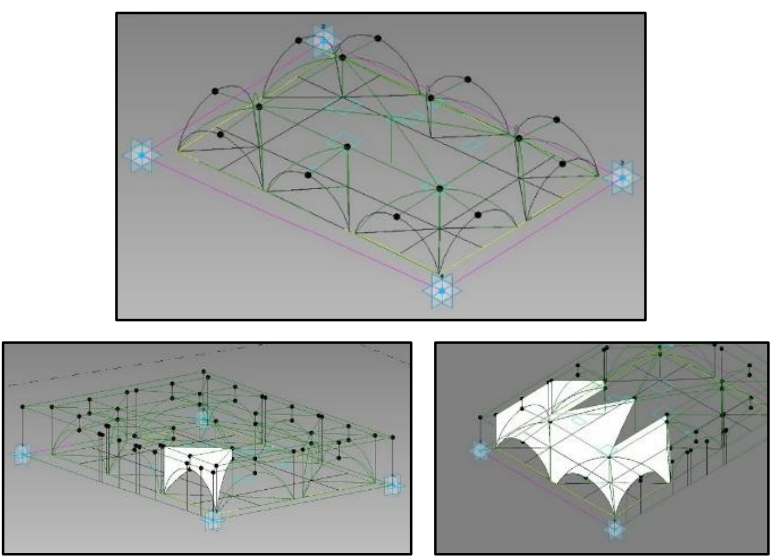

Figure 6. Modeling of the pavillon vaults and the lunettes
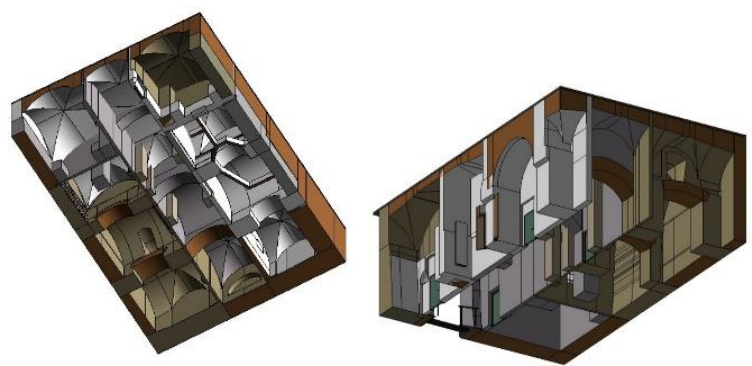

Figure 7. View of the HBIM

Surely this type of processing (semi-automatic) is time consuming and complex to realize. One of the goals after the modeling of the entire area of the origin of the castle has been the implementation of information of the instances of the model. The information Instance is data that describes the features that allow you to distinguish each object by another of the same type. In this case the reading of the architectural forms and in particular the dimensional characteristics of the vaults (height of the keys), has allowed us to identify the precise area of the first origin of the castle and that relative to the restoration dating the beginning of the seventeenth century .. The dating of the factory items has become information instance therefore they contribute to store information about the temporal stratification of the building.

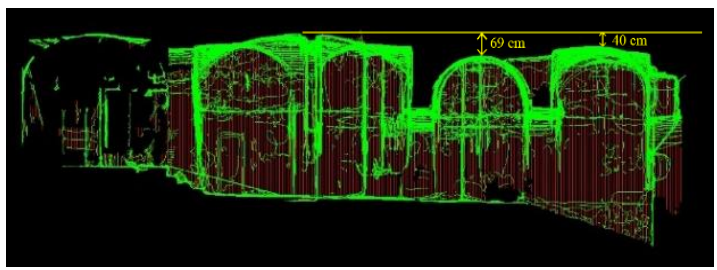




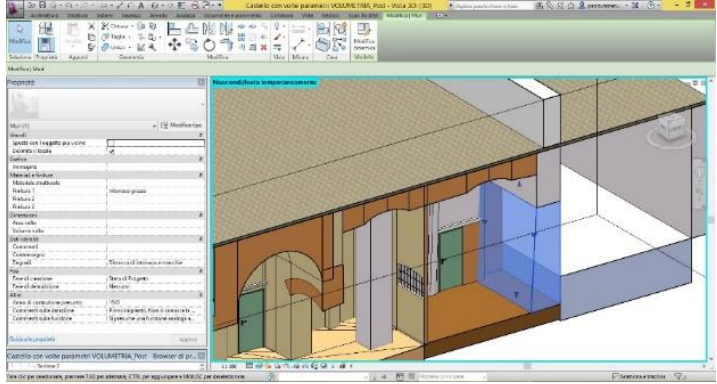

Figure 8. Time information into the model and analysis of the points clouds for verify temporal stratification

4.2.1 Case study that makes use of the automatic shape recognition. The second test area with which develops this study of the different types of modelling in BIM environment is directly related to the previous one, since it is the environment at the ground floor, placed exactly above the environments of the first plant of the castle. This is the "hall of columns" that has been modeled using the plugin Scan to BIM (IMAGINiT Technologies) for Revit software, able to recognize surfaces described by clouds of points.

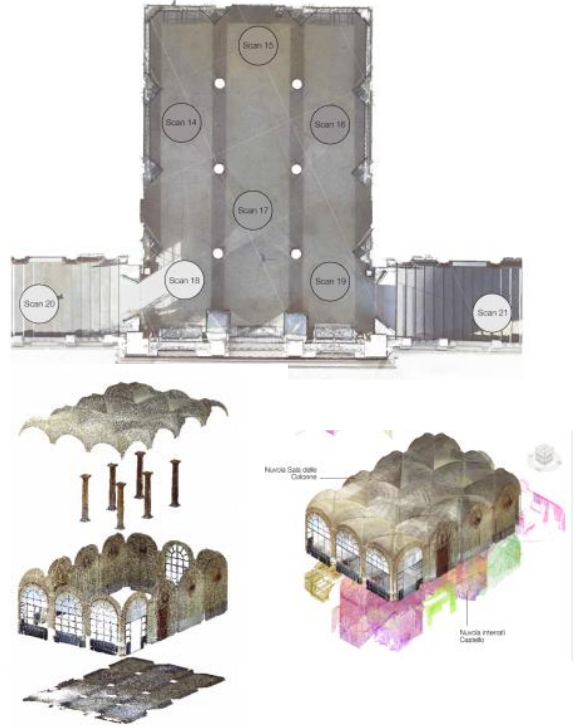

Figure 9. Point cloud segmentation before scan to BIM modelling in Revit
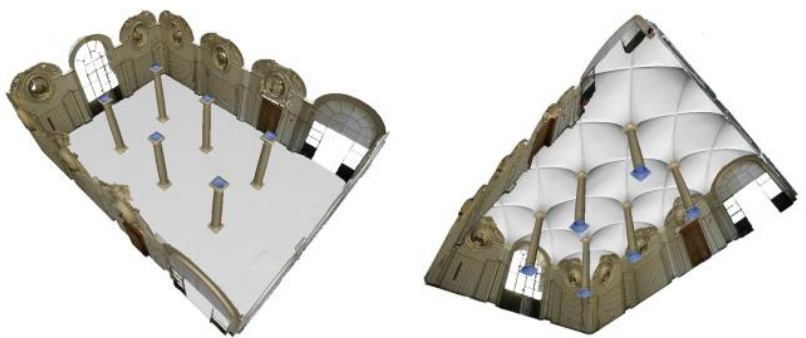

Figure 10. HBIM model of the "hall of columns"

Though a mesh model of the room was available, modeled from the point model into a software dedicated to the modeling of clouds (3D Reshaper), we approached to building the parametric model in Revit through the cloud interpretation. The following notes are intended in particular to provide a framework of clouds modeling, ie avoid similar steps to those seen in the previously. It should be emphasized that despite the "scan to BIM" software is particularly suitable for modeling MEP, additional features, from base use of Revit, facilitated the modeling of the hall of columns. Obviously all features of "scan to BIM" give us a model in a highly correspondence to the actual situation result, maintaining the high accuracy of the points cloud radiometric information determined with TLS. Since the point clouds are made up of millions of entities and the total weight is usually high, Revit, manages the clouds as external connections, rather than embedding the $*$.fle directly in the project. Another important feature of cloud management is that the reference system adopted during relief is not modified during the files import. This also allows in different time, to connect multiple laser scans, provided that it does not change the original reference system, which normally does not happen ever acting within the reality of the reality-based survey, whether that photogrammetry and laser scanning. Particularly useful was the Wall command, which requires to identify three well-distributed points on the vertical walls of the cloud. Automatically, it creates a through-work plan for the three selected points and on it the vertical element is generated. The next segmentation of the hall wall made it possible to create masonry units especially adapted to the surfaces of the cloud. The rich decoration of the hall walls (niches, mouldings, pilasters and stucco) was modeled by operating simplifications and using the families with which you can manipulate with the modeling tools Extrude, Revolve, Union, path Union, Sweep and Empties. As for the wall surfaces is exploited the recognition of the shape, as regards most of the decorative elements have been extracted the profiles from the cloud and it is operated semi-automatic parametric modeling.
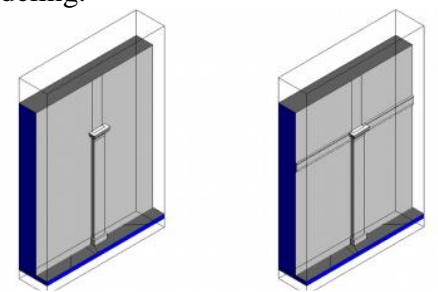

Figure 11. Modelling of pilaster and moulding in Revit space

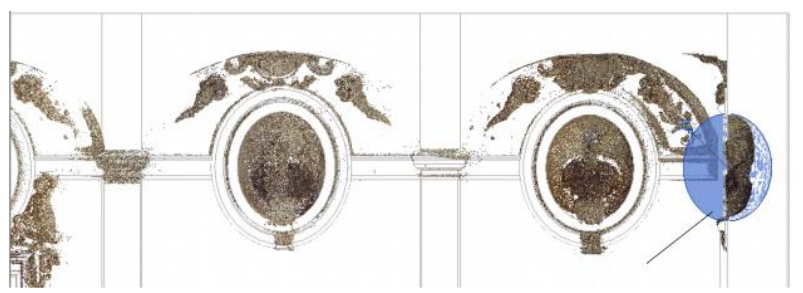

Figure 12. Creation of niche by subtraction solid.

The case of the columns has been treated with the loadable families. The slight differences between the columns and the capitals has been archived by modifying the parameters of family types. Loaded the family in the Project File, Round Columns command, contained in the Plug-in "Scan to BIM", lets you select an area, to identify the points in the cloud relative to linear vertical elements, such as pillars and columns.

Identified these items and choosing the loaded column Family, the item is automatically placed in the project.

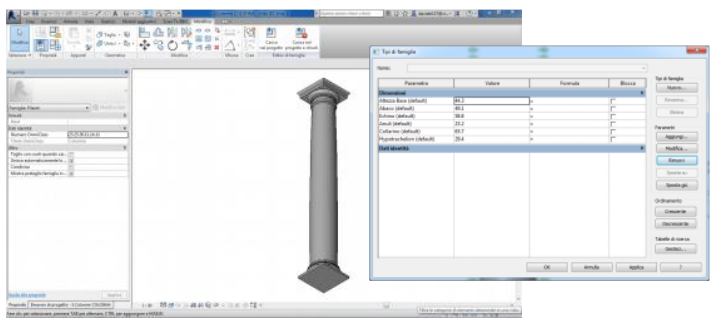


Figure 13. Modelling of the column by parametrization

The surface triangulation method has been operated effectively to the floor, to achieve a geometrically nearest surface to the real one, but it does not seem appropriate for surfaces with a complex geometry as the vaults ones. The subtraction of cylinders too is not effective to adapt to deviations from the geometric principle of real vaults. The most suitable method to modelling of historical vaulted surfaces proved to be the one presented in the previous paragraph.

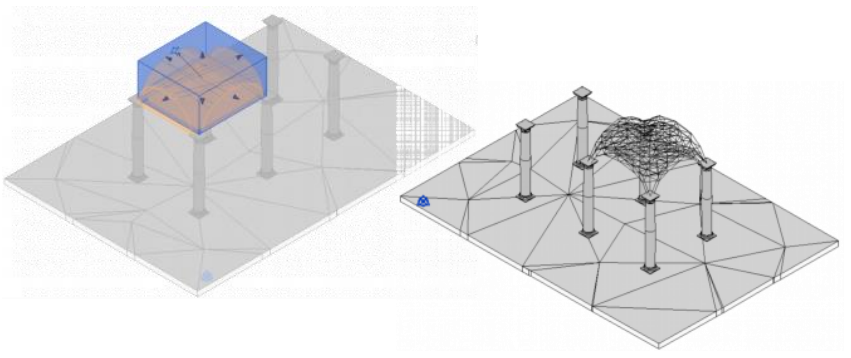

Figure 14. Ad-hoc modelling of the vaults

The use of adaptive generic model template for the construction of the vaults fixes difficulty for the recognition of the "hall of columns" environment by the system. It is therefore not possible.

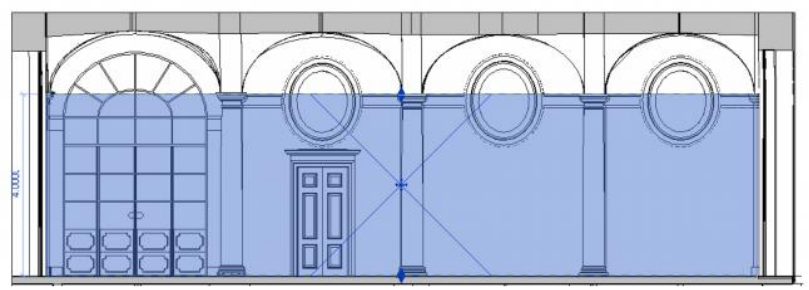

Figure 15. Trying to define the environment "Hall of columns" for generic adaptive model
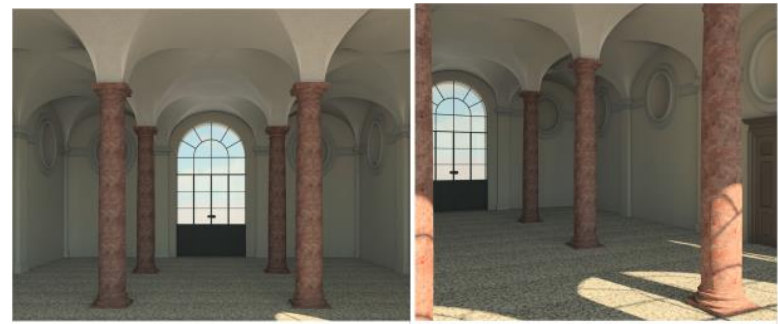

Figure 16. Rendering of the HBIM

\section{EXPLORE HBIM AS PARAMETRIC DATABASE: SHARING AND COMUNICATION}

The future of BIM in Cultural Heritage domain is surely the sharing and the portability of models different people and different scopes, to a wider user community with different purposes. Mobile device are today very useful to explore reality of Cultural Heritage and a tool to manage. Mobile BIM applications can be a valid tool for expert operators interested in the conservation process, whereas 3D models and virtual tours can be generated from the HBIM, without redrawing a new model for these specific purposes. The BIM can be therefore intended as a central tool for the accurate investigation of the building. (Barazzetti et al, 2015b)

\subsection{Managing 3D models: generic users and specialist operators}

It is needful to differentiate and pre-determinate models structure and embedded information to optimize preprocessing and knowledge modeling with the relative LoD.

From 3D survey to HBIM we can start from the same 3D data but produce models to:

- Museum installations and divulgation/popularization projects

- Specialists in architecture, restoration, structural engeneering. .

- from HBIM to 3D GIS and CityGML (Costamagna \& Spanò, 2013)

- VR/AR as a tool to share information and return the 3D model as a smart tool for ongoing updating in projects in which Heritage assets are involved among multiple experts

5.1.1 Test-cases of Augmented Reality. The ultimate experience that we want to display is one that covers a portion of the town of Pollenzo, (the ancient Pollentia), whose houses are built on the foundations of the Roman amphitheater, and therefore the urban structure retains the oval shape. Is the most ancient city of Tanaro Valley in South Piedmont and archaeological researches lightened that the roman village was extended south to the roman amphitheater, currently visible because of the village developed upon it. The documentation of the area was carried out by performing a photogrammetric survey by UAV and a TLS survey, but we focus only on the outcome of parametric modeling. Parametric modeling was performed using the software ArchiCAD, using rather traditional modeling methods, based in ArchiCAD for 3D surfaces. ArchiCAD uses GDL (Geometric Descriptive Language) that is a programming language, for 3D modeling of objects from primitive forms that contain the necessary information for the object parameter function. One of the software features is the versatility with which displays the entire point cloud or its parts and set the projection surface independently from that of the modeling work. The most important strategy was to create a mesh from the point cloud of the road pavement and build parametric models of buildings including all the architectural elements, making ample use of stored libraries and making extensive use of the return of polylines responding to point clouds and extruding in the necessary directions.

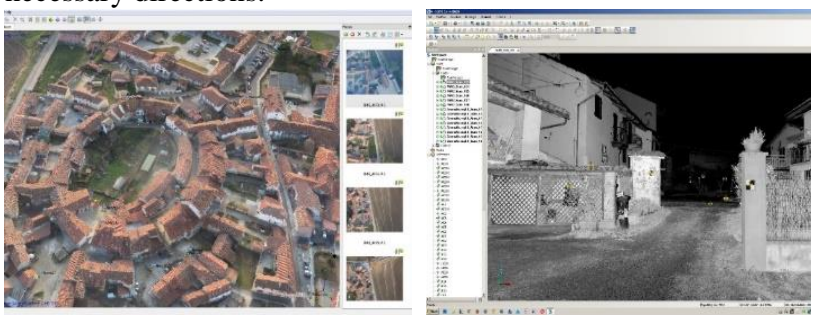

Figure 17. Images from the raw data: the point cloud from UAV photogrammetry, and TLS acquisition.

In ArchiCAD platform is also very useful the implementation of the big texture library.
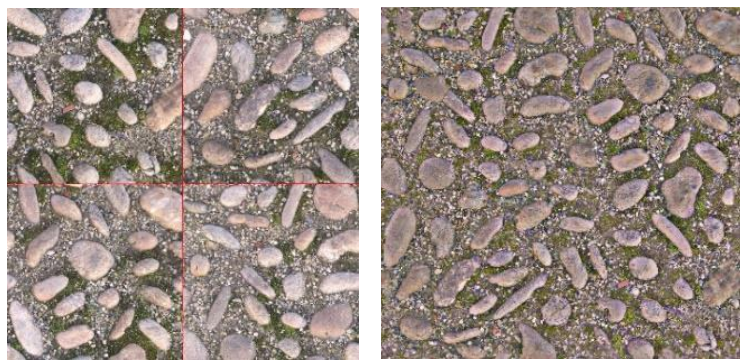
Figure 18. Creation of a tileable texture: right, casual reiteration of a digital image; left, casual reiteration of a tileable image
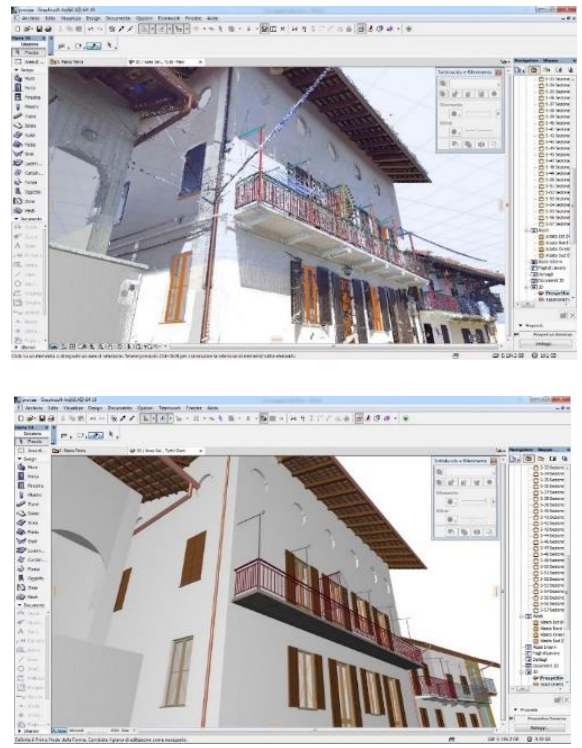

Figure 19. Modelling phases: from point clouds to HBIM

ArchiCAD is equipped by Cinerender application too, for creating photo-realistic rendering of $3 \mathrm{D}$ project views. BIMX application allows to view the entire model on PC, smartphone and tablet, permitting an easy distribution to professionals and other types of users. It is possible to navigate within the threedimensional into the model and query each component, accessing to the archives of information about materials, sizes and all useful data. They can be documented by the IFC of the Building Standard SMART attributes, or other implemented ad hoc.

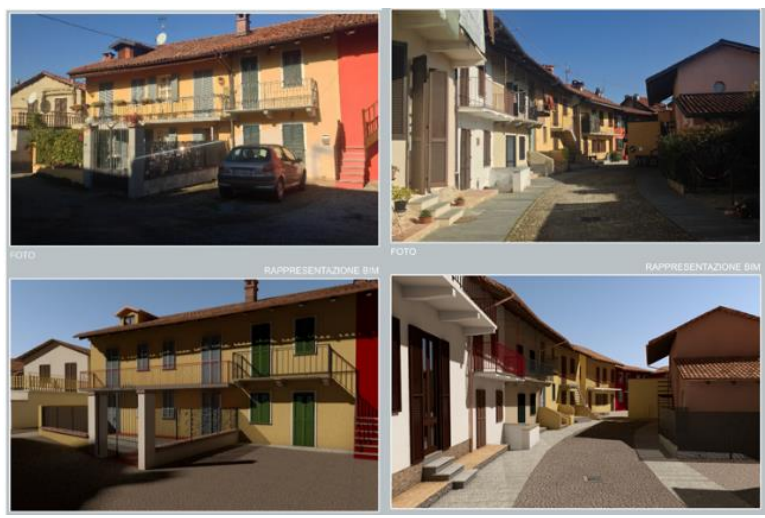

Figure 20. HBIM compared to reality. Top, pictures taken from Pollenzo; down, the corresponding model image

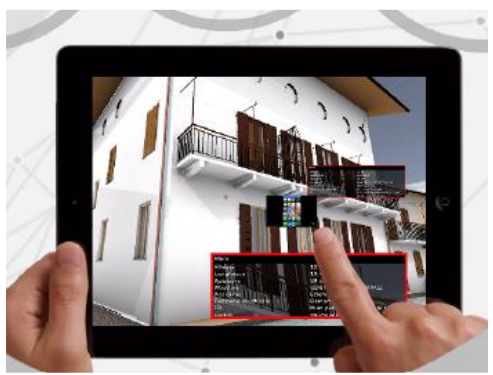

Figure 21. The handling of the HBIM model in a mobile device

\section{FUTURE PERSPECTIVES}

- Importance of pre-establishment aims and users of the HBIM: they are the variables on which will depend LoD and all the knowledge related to the model.

- Importance of STANDADS in languages and INTEROPERABILITY of format during entire workflow/steps for creation of HBIM, from 3D survey to database (Quattrini et al, 2015)

- Modelling is like a voluntary approximation of reality: take into account APPROXIMATION CHOICES in architectural shape modelling, in definition of historical buildings and in non-geometrical information association, more than common as-built BIM

- Focusing into realistic context of $\mathrm{CH}$ with cluttered scenarios and need of auto-recognition of artefacts and improper items

- Geomatics 3D techniques provide a complete database of preliminary information from which operator starts to create the HBIM. In acquisition phase, no specific choice of selection (3D survey aim to optimize all data collection). In pre-processing phase, a first approximation is possible in order to improve algorithms of auto recognition and segmentation.

- The research have to elaborate models aimed to be shared in 3D GIS and City models, as well as create portable models with differentiated information for specific users.

- Very interesting perspective, in the future, is the opportunity to provide to expert operators in AEC context, specifically in $\mathrm{CH}$, a PORTABLE model-database on a mobile device, "useroriented". The model can be useful to not only analyse the building with the information ex-post (High detailed model), but also create the Building Information Modeling directly on the site IN REAL-TIME, during the conservation and restoration phase (Less specific and handy model: it requires less LoD).

- How to extent HBIM on site via VR? (Quattrini et al, 2015)

\section{ACKNOWLEDGEMENTS}

The authors would like to thank especially E. Abbate D. Leoni, P. Raineri, M. Somano for their interest and works on the HBIM.

\section{REFERENCES}

Barazzetti, L.; Banfi, F.; Brumana, R.; Gusmeroli, G.; Oreni, D.; Previtali, M.; Roncoroni, F.; Schiantarelli, G., 2015a. BIM From Laser Clouds and Finite Element Analysis: Combining Structural Analysis and Geometric Complexity. In: The International Archives of the Photogrammetry, Remote Sensing and Spatial Information Sciences. 2015, XL-5/W4, 345-350

Barazzetti, L., Banfi, F., Brumana, R., Oreni, D., Previtali, M., and Roncoroni, F., 2015b. HBIM and augmented information: towards a wider user community of image and range-based reconstructions, In: The International Archives of the Photogrammetry, Remote Sensing and Spatial Information Sciences, XL-5/W7, 35-42

BIM FORUM, Level of Development Specifcation, 30/10/2015, p. 12. https://bimforum.org/lod/

Chevrier, C., Y. Maillard, et al. 2009. A method for the 3d modelling of historic monuments: the case of a gothic abbey. Proceedings of the $3^{\text {rd }}$ ISPRS International Workshop 3D-ARCH2009, Trento, Italy

Chiabrando, F., Donadio, E., Sammartano, G., Spanò, A., 2015. La tecnologia laser scanning per la valutazione statica delle strutture storiche. In: Proceedings of "Conferenza Nazionale ASITA 2015", Lecco, 29 Settembre - 1 Ottobre 2015. pp. 253-261

Costamagna, E., Spanò, A. 2013. CityGMLfor Architectural Heritage. Developments in Multidimensional Spatial Data Models. Springer Berlin Heidelberg, pp. 219-237. 
Del Giudice, M. and Osello, A., 2013. BIM for Cultural Heritage, CIPA Strasbourg: BIM for Cultural Heritage, The International Archives of the Photogrammetry, Remote Sensing and Spatial Information Sciences, XL-5/W2, 225-229.

C. Dore, M. Murphy, S. McCarthy, F. Brechin, C. Casidy, E. Dirix 2015. Structural Simulations and Conservation Analysis-Historic Building Information Model (HBIM). In: The International Archives of the Photogrammetry, Remote Sensing and Spatial Information Sciences. 3D Virtual Reconstruction and Visualization of Complex Architectures, 25-27 February 2015, Avila, Spain

Dore, C., Murphy, M., 2012. Integration of Historic Building Information Modeling and 3D GIS for Recording and Managing Cultural Heritage Sites, 18th International Conference on Virtual Systems and Multimedia: "Virtual Systems in the Information Society", 2-5 September, 2012, Milan, Italy, pp. 369-376.

Eastman C., Teicholz P., Sacks R., Liston K., 2008. BIM Handbook. A guide to Building Information Modeling for Owners, Managers, Designers, Engineers, and Contractors, Jonn Wiley \& Sons, Hoboken, New Jersey

El Meouche R., Rezoug M., HIJAZI Ihab, 2013. Integrating and managing BIM in GIS, software review, In: The International Archives of the Photogrammetry, Remote Sensing and Spatial Information Sciences. Volume XL-2/W2, ISPRS 8th 3DGeoInfo Conference \& WG III/2 Workshop, 27 - 29 November 2013, Istanbul, Turkey

Fai S., Graham K., Duckworth T., Wood N., Attar R., 2011. Building Information Modeling and Heritage Documentation, CIPA Conference Proceedings: XXIII International CIPA Symposium, Prague.

Fai, S., Rafeiro, J., 2014. Establishing an Appropriate Level of Detail (LoD) for a Building Information Model (BIM)-West Block, Parliament Hill, Ottawa, Canada. In: The International Archives of the Photogrammetry, Remote Sensing and Spatial Information Sciences, 1, 123-130.

Garagnani, S. Manferdini, A. M. 2013. Parametric accuracy: building information modeling process applied to the Cultural Heritage preservation. In: The International Archives of the Photogrammetry, Remote Sensing and Spatial Information Sciences, Volume XL-5/W1, 2013 3D-ARCH 2013, 25 - 26 February 2013, Trento, Italy

N. Hichri, C. Stefani, L. De Luca, P. Veron, G. Hamon, 2013. From point cloud to BIM: a survey of existing approaches. In: The International Archives of the Photogrammetry, Remote Sensing and Spatial Information Sciences, Volume XL-5/W2, XXIV International CIPA Symposium, 2 - 6 September 2013, Strasbourg, France

ISO standard 29481-1: 2010 (E) Building information modelling Information delivery manual - Part 1: Methodology and format

Lari Z., Habib A. F., Kwak E., 2011. An adaptive approach for segmentation of $3 \mathrm{~d}$ laser point cloud, In: The International Archives of the Photogrammetry, Remote Sensing and Spatial Information Sciences, Volume XXXVIII-5/W12, pp. 103-108

Leoni, D. 2016, Tecnologie LiDAR e HBIM: una proposta applicata al Castello del Valentino, MSc thesis, tutors Spanò, Chiabrando, Politecnico di Torino.

Logothetis, S., Delinasiou, A., and Stylianidis, E., 2015. Building Information Modelling for Cultural Heritage: A review, In: The International Archives of the Photogrammetry, Remote Sensing and Spatial Information Sciences, II-5/W3, 177-183

M. Ludwig, G. Herbst, D. Rieke-Zapp, R. Rosenbauer, S. Rutishauser, A. Zellweger, 2013. The advantages of parametric modeling for the reconstruction of historic buildings. The example of the in war destroyed church of St. Catherine (Katharinenkirche) in Nuremberg.
In: The International Archives of the Photogrammetry, Remote Sensing and Spatial Information Sciences, Volume XL-5/W1, 2013 3D-ARCH 2013, 25 - 26 February 2013, Trento, Italy

M. Murphy, E. McGovern, S. Pavia, 2012. Historic Building Information Modelling - Adding intelligence to laser and image based surveys of European classical architecture, In: The International Archives of the Photogrammetry, Remote Sensing and Spatial Information Sciences

Murphy, M, McGovern, E, Pavia, S., 2009, Historic Building Information Modelling (HBIM), Structural Survey, vol. 27, no. 4, pp. $311-27$.

National Institute Of Building Science, United States. National Building Information Modeling Standard. Version 3-2015. www.nationalbimstandard.org

Open Geospatial Consortium Inc. 2008, OpenGIS ${ }^{\circledR}$ City Geography Markup Language (CityGML) Encoding Standard, Open Geospatial Consortium Inc., Berlin. http://www.opengeospatial.org

Oreni D., Brumana R., Della Torre S., Banfi F., Barazzetti L., Previtali M, 2014. Survey turned into HBIM: the restoration and the work involved concerning the Basilica di Collemaggio after the earthquake (L'Aquila). In: The International Archives of the Photogrammetry, Remote Sensing and Spatial Information Sciences, Volume II-5, ISPRS Technical Commission V Symposium, 23 - 25 June 2014, Riva del Garda, Italy

D. Oreni, R. Brumana, A. Georgopoulos, B. Cuca, 2013. HBIM for conservation and management of built heritage: towards a library of vaults and wooden bean floors. In: The International Archives of the Photogrammetry, Remote Sensing and Spatial Information Sciences, Volume XL-5/W2, XXIV International CIPA Symposium, 2 - 6 September 2013, Strasbourg, France

R. Quattrini, E. S. Malinverni, P. Clini, R. Nespeca, E. Orlietti, 2015. From TLS to HBIM. High quality semantically-aware 3D modelling of complex architecture. In: The International Archives of the Photogrammetry, Remote Sensing and Spatial Information Sciences, Volume XL-5/W4, 2015 3D Virtual Reconstruction and Visualization of Complex Architectures, 25-27 February 2015, Avila, Spain

Raineri, P., 2015, L'approccio BIM (Building Information Modeling) per la documentazione dell'Architettura storica. Una proposta applicativa al Castello del Valentino, MSc thesis, tutors Spanò, Chiabrando, Politecnico di Torino.

Saygi, G., Agugiaro, G., Hamamcioğlu-Turan, M., Remondino, F., 2013. Evaluation of GIS and BIM roles for the information management of Historical Buildings. In: The International Archives of the Photogrammetry, Remote Sensing and Spatial Information Sciences, II-5/W1, 283-288, isprsannals-II-5-W1-283-2013.

Somano, M. 2015, Dalla nuvola di punti al BIM. Sperimentazioni sull'anfiteatro romano di Pollenzo, MSc thesis, tutors Chiabrando, Spanò, Politecnico di Torino.

Sun, Z. and Cao, Y. K., 2015. Data processing workflows from lowcost digital survey to various applications: three case studies of Chinese historic architecture, In: The International Archives of the Photogrammetry, Remote Sensing and Spatial Information Science, XL-5/W7, 409-416.

Tang, P., Huber, D., Akinci, B., Lipman, R., Lytle, A., 2010. Automatic reconstruction of as-built building information models from laserscanned point clouds: A review of related techniques, Automation in Construction, Volume 19, Issue 7, November 2010, pp. 829-843

Volk, R.; Stengel, J.; Schultmann, F. 2014. Building Information Models (BIM) for existing buildings-literature review and future needs. Automation in Construction 38, pp.109-127 